\title{
Keeping the Actors in the Organic System Learning: The Role of Organic Farmers' Experiments
}

\author{
Christian R. Vogl ${ }^{1}$, Susanne Kummer ${ }^{1}$, Friedrich Leitgeb ${ }^{1}$, Christoph Schunko ${ }^{1} \&$ Magdalena Aigner ${ }^{1}$ \\ ${ }^{1}$ Division of Organic Farming, Department of Sustainable Agricultural Systems, University of Natural \\ Resources and Life Sciences Vienna (BOKU), Austria \\ Correspondence: Christian R. Vogl, University of Natural Resources and Life Sciences Vienna (BOKU), \\ Gregor-Mendel-Strasse 33, A-1180 Vienna, Austria. E-mail: christian.vogl@boku.ac.at
}

Received: March 7, 2015 Accepted: May 19, 2015 Online Published: June 20, 2015

doi:10.5539/sar.v4n3p140 URL: http://dx.doi.org/10.5539/sar.v4n3p140

\begin{abstract}
The creative process that leads to farmers' innovations is rarely studied or described precisely in agricultural sciences. For academic scientists, obvious limitations of farmers' experiments are e.g. precision, reliability, robustness, accuracy, validity or the correct analysis of cause and effect. Nevertheless, we propose that 'farmers' experiments' underpin innovations that keep organic farming locally tuned for sustainability and adaptable to changing economic, social and ecological conditions. We first researched the structure and role of farmers' experiments by conducting semi-structured interviews of 47 organic farmers in Austria and 72 organic/agroecology farmers in Cuba in 2007 and 2008. Seventysix more structured interviews explored the topics and methods used by Austrian farmers that were 'trying something'. Farmers engaged in activities that can be labelled as farmers experiments because these activities include considerable planning, manipulating variables, monitoring effects and communicating results. In Austria and Cuba 487 and 370 individual topics, respectively, were mentioned for experimenting by the respondents. These included topics like the introduction of new species or varieties, testing various ways of commercialization or the testing of alternative remedies. Two thirds (Austria) and one third (Cuba) of the farmers who experimented had an explicit mental or written plan before starting. In both countries, the majority of the farmers stated that they set up their experiments first on a small scale and expanded them if the outcome of the experiments was satisfactory. Repetitions were done by running experiments in subsequent years and the majority of the farmers monitored the experiments regularly. In both countries, many experiments were not discrete actions but nested in time and space. For further research on learning and innovation in organic farming we propose an explicit appreciation of farmers' experiments, encouraging further in-depth research on the details of the farmers' experimental process and encouraging the inclusion of farmers' experiments in strategies for innovation in organic and non organic farming. Strategic research and innovation agendas for organic farming would benefit from including organic farmers as co-researchers in all steps of the research process in order to encourage co-learning between academic scientists and organic farmers.
\end{abstract}

Keywords: organic agriculture, innovation partnership, collective action, co-research, participatory research, co-enquiry, collaborative learning

\section{Introduction}

\subsection{The Importance of Innovation}

The performance of agriculture worldwide clearly shows that the current mainstream agricultural pathway is not sustainable, causing a diversity of ecological, social and economic problems (McIntyre et al., 2009). Currently, innovation (e.g. Smits et al., 2010; EU SCAR, 2012) is seen as the buzzword and the key concept for supporting the urgently needed pathways or transition towards sustainability (van de Kerkhof \& Wieczorek, 2005) or towards resilient societies (Folke et al., 2010; Leach et al., 2012), particularly in organic farming. Organic farming has contributed to multiple aspects of sustainability, especially concerning (new/innovative) on-farm production methods (Darnhofer, 2014a, Moeskops et al., 2014).

For a long period of time the term 'innovating' was mainly associated with science or commercial enterprisess. Recently the focus has shifted and clear evidence has been presented, that innovation is a dynamic social multi-stakeholder process that implies the participation of a diversity of stakeholders (Smits et al., 2010). Today, 
participatory action research (McIntyre, 2007; Chevalier \& Buckles, 2013), citizen science (Tulloch et al., 2013) or transdisciplinary research (Tress et al., 2005; Mittelstraß, 2011) are state of the art approaches for ensuring that not only local knowledge, but also creativity and enthusiasm from all stakeholders linked to a certain topic are involved and taken seriously in the related research and innovation pathways.

In the agricultural sciences sector the debate on the role of stakeholders in providing information, sharing knowledge and supporting innovation is far advanced and has been framed in various models like e.g. in the Agricultural Knowledge and Information System or the Agricultural Innovation System, i.e. AKIS or AIS (e.g. Rivera et al., 2005; Spielmann, 2008). Nevertheless, the creative process that leads to farmers' innovations is rarely studied nor described precisely in agricultural sciences e.g. in syntheses on Agricultural Knowledge and Innovation Systems (EU SCAR, 2012) and in policy papers on innovation in organic farming (Moeskops et al., 2014).

The concepts currently used for describing what leads to farmers innovations are e.g. 'problem solving', 'innovating' or 'self help' (Moeskops et al., 2014). These terms are however used ambiguously and imprecisely, which might easily lead to ignoring the complexity of the processes involved. A lack of knowledge of this genuine creative process of 'innovating' might also lead to ignoring the intervening factors, misplacing the key incentives and thus not sufficiently taking into account the opportunities for encouraging farmers' innovations especially in organic farming.

\subsection{Farmers' Experiments}

In this paper we pick up and propose the concept of farmers' experiments as one option for describing the creative process that might lead to farmers' innovations. Yet, an experiment in general is defined as 'a course of action tentatively adopted without being sure of the outcome' (ODO, 2010) or 'a test or series of tests in which purposeful changes are made to the input variables of a process or system so that we may observe and identify the reasons for changes that may be observed in the output response' (Montgomery, 2009). Farmers' experimentation is the process by which farmers informally conduct trials or tests that can result in new knowledge and innovative management systems suitable for their specific agro-ecological, socio-cultural and economic conditions (Rajasekaran, 1999). Sumberg and Okali (1997), who did pioneer work on farmers' experiments, consider two conditions necessary for an activity to be labelled an experiment: the creation and initial observation of conditions, and the observation or monitoring of subsequent results.

\subsection{Links to Organic Farming}

There are two reasons why it is particularly interesting to explore farmers' experiments in the context of organic farming.

First, sustainable land use practices are more knowledge-intensive (Röling \& Brouwers, 1999). While conventional farmers can use external inputs such as synthetic pesticides and synthetic fertilisers to handle adverse dynamics in their agro-ecosystem, organic farmers need to develop knowledge about the agro-ecosystem to a larger extent to be able to manage their farms successfully without these inputs.

Second, organic agriculture was developed by farmers and farmers' grassroots organisations. Academic science and research only played a minor role in the historical development of organic agriculture (Padel, 2001), and organic farming was developed by practical experiments and trials of farmers and practical researchers. The lack of advice and formal research in the pioneer phase of organic agriculture leads to the assumption that organic farmers have nurtured a culture of experimentation. Organic farmers in the pioneer phase can be referred to as active experimenters and practical researchers (Gerber et al., 1996).

To our assumption it was not only the pioneers of organic agriculture who experimented; many organic and non-organic farmers worldwide are presumably still actively trying and experimenting to answer questions and solve problems that emerge continuously. We were interested in addressing this assumption in field sites that are very different from each other and assessing if and to which extent organic farmers realize activities that can be called farmers' experiments. We focus on experiments carried out by farmers on their own initiative, and we explicitly avoid referring to on-farm research.

We want to contribute to the current debate on the elements needed for encouraging innovation in organic farming. We do so by presenting empirical evidence from Austria and Cuba that farmers' experiments are a key element of innovating at farm level and by discussing the potential role of farmers' experiments in the innovation process. 


\section{Case Studies and Method}

Austria and Cuba were selected for field research (together with Israel; Data on Isreael not presented here) due to various criteria that cause variation between the study sites. Austria has a long history of third party certified organic farming under a formal regulatory and policy framework and is an industrialized country in a temperate climate with high availability of farm inputs and formal advisory on organic farming; Cuba counts with a well organized but relatively young agroecology movement, which is the national interpretation of organic farming, and is a tropical country with limited availability of farm inputs (Kummer et al., 2012) in prep; Leitgeb et al., 2011, 2014).

Field research in Austria and Cuba started with semi-structured interviews (Austria: $\mathrm{n}=47$; Cuba $\mathrm{n}=72$; both in 2007 and 2008) based on samples of farmers with maximum variation (criteria for variation e.g.: region, different production types) for learning the terminology and aspects related to the topic of 'changes at farm level' and 'trying something'). Semi-structured interviews were digitally recorded, transcribed with the software ExpressScribe, and processed with the software Atlas.ti. We used qualitative content analysis, employing a combination of deductive and inductive coding for learning on such aspects as the topics, methods, outcomes, attitudes and beliefs related to the process of trying, testing, changing 'something' at farm level. We expected that the term 'experiment' might be loaded with the connotation of a scientific procedure (Sumberg \& Okali, 1997, p. 58). It was therefore agreed not to use that term during the semi-structured interviews to prevent narrowing the research field with this specific, technical connotation. The terms we used to refer to experimentation activities during interviews were 'to try, to try something, to try something new' (the terms we used in German were 'etwas probieren' or 'etwas ausprobieren', in Spanish: 'probar algo').

Based on insights from these semi-structured interviews a structured questionnaire was set up with pre-defined answer categories on all elements of experimentation identified. In the structured interviews, in contrast to the semi-structured interviews before, the conversation was started with the purposeful introduction of the term 'experiment', including a definition that was based on the results of the semi-structured interviews. The structured interviews were applied in Austria with 76 organic farmers in 2008 and 2012 and in Cuba with 34 farmers from the Cuban Agroecology Movement and the Cuban Urban agriculture movement in 2007 and 2008. Structured interviews from Austria were digitally recorded, data inserted into a Microsoft-Access database, and later descriptively analyzed with Microsoft-Excel and SPSS, from Cuba this data set has not yet been analyzed.

Here selected qualitative descriptive data is presented summarizing the results from Kummer et al. (2012, 2015 in prep) and Leitgeb et al. $(2011,2014)$.

\section{Results}

In Austria the interviewees in semi-structured and structured interviews (together $n=123$ ) mentioned 487 individual topics for experimenting and only eight interviewed farmers stated that they had never carried out any activity that they would define as 'trying something'. In Cuba 370 individual topics were mentioned by all farmers in semi-structured interviews.

Aspects in crop production (e.g. introduction of new species or varieties) were the most frequently mentioned topics in Austria and Cuba, but literally all aspects are to be found, and even commerzialization, construction, testing of alternative remedies or the influence of the lunar cycle, or social organisation were under the topics mentioned by the Austrian and Cuban farmers for doing experiments.

The most frequently mentioned motives for doing experiments were in both countries personal reasons and overcoming challenges or problems. Challenges frequently cited in Cuba were e.g. increasing productivity or achieving independence from external resources. Personal reasons included a general interest in a specific topic or curiosity about how something could work or not, and also the opinion that implementing a specific practice on the farm would be meaningful and desirable for the respective person. Farmers in both countries mentioned most frequently other farmers as sources for information needed for the experiment and also as sources for ideas, together with literature or advisors.

In Austria, two thirds of the farmers who experimented had an explicit mental or written plan before starting. In Cuba one third of the respondents had precise plans, partly in a written way based upon detailed criteria. In both countries, the majority of the farmers stated that they set up their experiments first on a small scale and enlarged them if the outcome of the experiments was satisfactory. Repetitions were done by running experiments in subsequent years between two and five years long, partly longer but without documenting the duration by our respondents.

In both countries the majority of the farmers monitored the experiments regularly, mostly through observation 
and comparisons (e.g. with previous experiences, with other farmers, with another unit at the own farm, etc.). Only a small proportion of farmers did measurements. Documentation strategies included taking notes, pictures, samples or videos.

In both countries, many experiments were not discrete actions but nested in time and space: One specific experiment can be the source of information or motivation for another specific experiment, experiments can be carried out simultaneously and a 'smaller' topic under experimentation can be part of a 'bigger' topic under experimentation.

In Austria farmers most frequently reported as outcomes of their trials having obtained more knowledge, having learned and increased satisfaction, but also having reduced the work load, increased production, gained reputation or increased income. Increased productivity, increased self sufficiency and better work efficiency were the most frequently mentioned outcomes in Cuba. First addresses for disseminating outcomes were other farmers in both countries. Having learned was attributed by the farmers even to failures or flops in experimenting.

In Cuba, experimentar (experimenting) and experimento (experiment) were terms frequently used by farmers when answering to our questions about 'trying something'. This was different from Austria where etwas ausprobieren (to try something) was the most common phrase used. In Cuba, experimentación campesina (farmers' experiments) was an integral part of the Cuban agroecology movement and therefore understood by most of the respondents as a concept and as a practical daily activity. Experimentation, innovation and inventions at farm level are part of the Cuban discourse on rural development and encouraged explicitely e.g. through competitions for the best innovation or invention at municipal, provincial and national level, including awarding them for innovations or supporting the negotiations for achieving a patent for promising inventions. In Austria, a formal discourse on farmers' experiments in the organic farming movement or under organic farmers, even when talking about 'to try something' could not be observed during the study period.

\section{Discussion}

With data from Austria and Cuba we can empirically confirm findings of e.g. Sumberg and Okali (1997) that farmers engage in activities of 'trying something'. These activities can be called farmers' experiments as they include to a considerable proportion planning, implementing variables of unknown consequences in search for their effects, monitoring the effects, and communicating results.

Various authors draw diverse conclusions about the significance of farmers' experiments, but most of the authors agree that all farmers have experimental capacity (e.g. Rhoades \& Bebbington, 1991; Chambers, 1999; Quiroz, 1999; Critchley \& Mutunga, 2003; Bentley, 2006, 2010), and that experiments are an integral part of farming activities (Sumberg et al., 2003). The experimental capability of farmers, similarly to the resilience of farms, cannot be regarded simply as an automatic response being deducted from the farms' characteristics, but it is rather the ability to identify opportunities, implement options and to 'learn as part of an iterative, reflexive process' (Darnhofer, 2014b).

However, this does not mean that all farmers are innovative (Quiroz, 1999). Experimenting farmers are rarely a homogeneous group. They have been found to be both resource-rich and resource-poor (Saad, 2002), both men and women, both outsiders and well-integrated, and both highly educated and less educated (Reij \& Waters-Bayer, 2001). Farmers conduct experiments to test their ideas in their own way (Rajasekaran, 1999). Experimentation can be induced by intuition, curiosity or by an explicit desire to learn (Stolzenbach, 1999). Farmers can be driven by economic motives as well as by a concern for production, and saving labour or capital (Critchley, 2000; Bentley, 2006). While new ideas and changes spark creativity and induce experiments, the capacity to experiment and learn also depends on prior knowledge and experiences. The source of farmers' experiments is therefore a combination of prior local/traditional knowledge of the farmer and new information the farmer aquires from elsewhere (Bentley, 2006).

Based on our findings and literature, we propose a theoretical model of the experimentation process (Figure 1) that helps elucidating what usually just has been vaguely called 'problem solving', 'innovating' or 'self help (Moeskops, 2014). When a certain problem or topic arises, a farmer can decide to adopt an available solution to deal with the situation (Wortmann, 2005), without entering an experimentation process. If the farmer decides to start an experiment, he or she can adapt a common solution that is already known to him or her (Wortmann, 2005; Pretty, 1995), or can decide to try something new. The experimentation process can be defined as a research process that involves a specific methodological approach, including setup, monitoring of the process and evaluation of the results. Different factors, such as environmental, economic or social conditions influence the experimentation process (Sumberg \& Okali, 1997), and have an effect on the experiment. Interrelations also exist with regard to the communication system in which the farmer is involved: farmers use local knowledge from 
their own farm in combination with knowledge from other sources, such as other farmers, media, science or advisory services (Stolzenbach, 1999; Bentley, 2006; Sturdy et al., 2008; Leitgeb et al., 2011). The results of an experimentation process can be classified into innovations, inventions or 'failures' (the later being learning experiences but not involving any change at farm level). These results are usually communicated to the social network of the farmers, such as e.g. family, neighbors or advisors. They are also fed back into the planning and implementation of new experiments to be realized by the farmer.

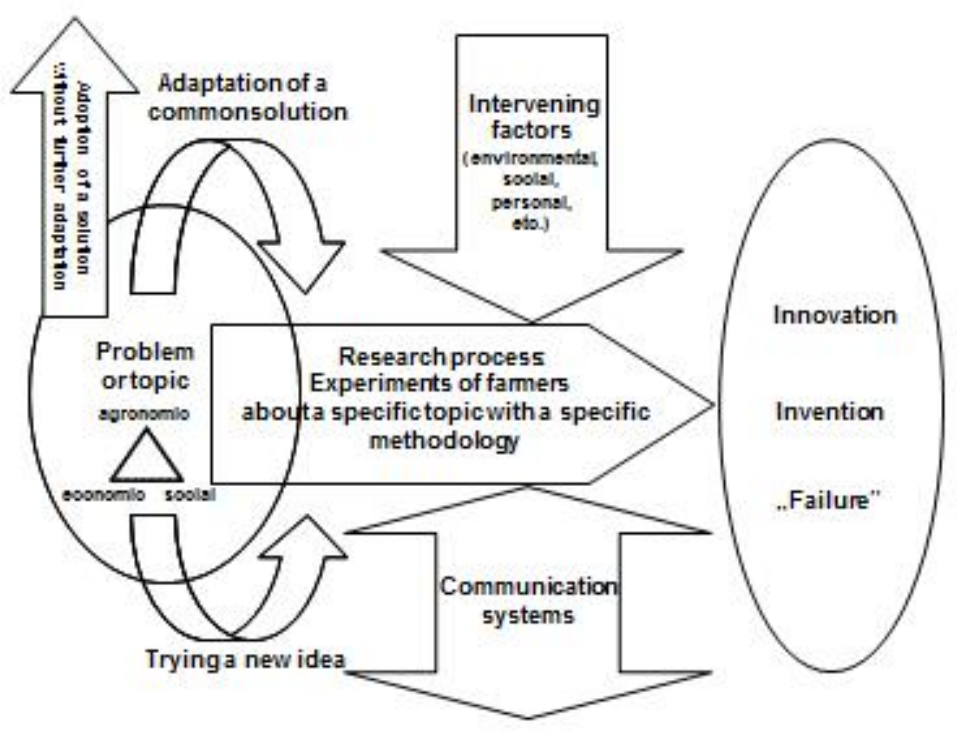

Figure 1. Model adapted from Ninio and $\operatorname{Vogl}$ (2006) for operationalizing the topic of farmers' experiments

Farmers, at least in Austria, themselves hardly use the term 'experiment' to refer to their practical on-farm experiments, but relate this term more to a scientific and formal procedure. In various empirical studies on the topic, using the term 'trying' instead of 'experimenting' in interviews has been seen as being more expedient (Sumberg \& Okali, 1997), while in other cases local terms are used to address the subject in the field (Stolzenbach, 1999). Other terms used in literature are i) 'farmer research', which refers to 'research conducted by farmers for discovery or production of information' (Wortmann et al., 2005) and ii) 'on-farm research', which means research conducted, and usually also controlled, by scientists on farms, involving the farmer more or less actively (Lawrence et al., 2007).

The topic of this paper was discussed during various oral presentations and poster presentations with peer scientists. In such discussions we often observed that scientists can be quite reluctant in accepting that the term experiment may be used also by actors not affiliated to academic science, and that e.g. farmers carry out their own experiments. For academic scientists, obvious limitations of farmers' experiments are e.g. precision, reliability, robustness, accuracy, validity or the correct analysis of cause and effect. To our assessment based on our results, but also confirmed e.g. by Moller (Henrik Moller, personal communication, November $2^{\text {nd }}, 2014$ ), comparative weakness of the farmers' experiments compared to the formal science experiments often include:

a) Lack of or poor spatial and temporal replication;

b) Few treatments, usually one at a time;

c) Reliance on a 'Before-After' comparison for detection of an experimental effect. Many farmer's experiments reject or accept an innovation/change if it works/doesn't work after a year or two - whereas ecological systems often display time-treatment interaction effects (what works now may not work in a different year and vice versa).

d) Poor quantification.

Most formal science is expensive, often aimed at a more general level of question, integrates and tries to find truth over a wide spatial scale (synchronic strength) over short investigation spans (diachronic weakness). In 
contrast, for farmers limitations of academic experiments might be the appropriateness of the design or the applicability of the results to the site specific conditions of a certain farm, and the lack of assessment under the complexity of annually changing farm conditions. Farmers' experiments are referenced against a long and culturally transmitted knowledge of how their local farm performed before the innovation was tried (diachronic strength) but may be less applicable to other farms, even ones nearby (synchronic weakness). Despite these weaknesses discussed in academia, for farmers their site specific experiments allows:

a) Local tuning of farmers' practice to the opportunities, threats and conditions of:

- Ecology and biophysical features of the land and landscape (soil, climate, environmental history);

- Social needs and capacity for change (what works for the farmers' view and values);

- Economic resilience (financial capacity and equity, resilience to experiment and ride through failed experiments, financial drivers to improve a weak part of their economic performance);

- Governance-constraints (policy, regulations, view of their co-owners or sector co-operative).

b) Building resilience by increasing adaptability in a changing world - the keys to capturing new opportunities and counteracting new threats.

c) Immediate uptake - because the practitioners act as free agents to initiate and conduct the experiments, we know them to be relevant, of keen interest and likely to be immediately heeded by the main decision makers on the farmer - this removes the main barrier to external expert driven research actually being used.

For further research and theory building on learning and innovation in organic farming we propose to avoid replacing academic experiments with farmers' experiments, or putting higher values on farmers' experiments than on academic experiments. First, we call for an explicit appreciation of farmers' experiments and encourage further in-depth research on the details of the experimental process and the related intervening variables of farmers' experiments. Second, we want to encourage the inclusion of farmers' experiments in strategies for innovation in organic farming. Strategies could be on-farm research or participatory research as proposed by Moeskops and Cuoco (2014).

Nevertheless, intensity and kind of participation can vary significantly (Pretty, 1999). On-farm research might also be called as such when farmers simply provide land to academic scientists for academic experiments, and the degree of 'participation' might vary considerably. Both on-farm research as well as participatory research have the potential that the role of farmers remains quite passive and ignoring their experimental capacity.

Strategic research and innovation agendas for organic farming and food (Moeskops \& Cuoco, 2014) must see organic farmers not only as actors providing the land for academic research, but farmers shall be included as co-researchers in various steps of the research process such as analyzing literature and empirical experiences, formulating research questions, developing the research design, monitoring, analysis and dissemination of results. Here farmers can learn about aspects such as accuracy and validity of research designs, while scientists might benefit e.g. from a holistic research design and monitoring that can include factors beyond measuring controlled variables, and in doing so learning from farmers how to deal with complexity (comp. Hoffmann et al., 2007). The usefulness of stakeholder participation in agricultural research was highlighted before and comprehensive participation frameworks were suggested to guide the participation process through self-reflection, informed discussion, and decision-making between project participants. These frameworks help to decide upon strengths and weaknesses of stakeholder inclusion in the steps of the research process and transcend common perceptions of the more participation the better (Neef \& Neubert, 2011). Research done by Sewell et al. (2014) showed that farmers' learning can be highly promoted when farmers participate in a learning community with scientists and become part of a shared inquiry, because 'dialogue is not only a means of communication, but it is also a means to generate new ideas, negotiate understandings and build knowledge' (Sewell et al., 2014). Care has to be taken by the organic movement that standards and regulations encourage, but do not hamper farmers' experiments (Vogl et al., 2005).

Co-learning and co-production of knowledge (Akpo et al., 2014; Sewell et al., 2014) between organic farmers and academic scientists do have a yet underestimated and underused potential in opening the creative potential for innovations in organic farming. The potential might even increase by opening the scope from the farm perspective to a perspective on the whole supply chain of certain products or to a regional perspective and involving the stakeholders along the chain or in the region.

Organic farmers should not only be perceived as beneficiaries of innovations through cutting edge basic science or scientific experiments, or as hosts for on-farm experimentation, but also be explicitely supported in their 
capacity of being experimenters and perceived as genuine co-researchers. 'Farmers cannot resist tinkering with new techniques. They will do this whether outsiders tell them to do so or not, regardless of any project or agency's philosophy. Farmers are experimenters, no matter what happens, even if outsiders do not encourage them to do so' (Bentley et al., 2010).

We believe that more sustainable and resilient farming can emerge from better listening and integration of the practitioners' ways of knowing with the structured experiments of agronomists. Complementarity between farmers' and academics' experiments forms a strong partnership of approaches that collectively opens a wider choice set for farming practice options and local tuning. Together the most robust and lasting knowledge will emerge, but at the moment the two types of expert rarely communicate with each other.

\section{Acknowledgments}

Research on farmers' experiments in Austria and Cuba was funded by the Austrian Science Fund (FWF) under the grant number P19133 G14_01. Inputs for the paper came from the debate at the conference 'Innovations in Organic Food Systems for Sustainable Production and Enhanced Ecosystem Services' in Long Beach/California (USA) in November 2014. The participation of the first author at this conference was funded by the OECD's Co-operative Research Programme (CRP) on Biological Resource Management for Sustainable Agricultural Systems. We are also very grateful for the debate on our topic with Henrik Moller and for his suggestions to our manuscript.

\section{References}

Akpo, E., Crane, T. A., Vissoh, P. V., \& Tossou, R. C. (2014). Co-production of knowledge in multistakeholder processes: Analyzing joint experimentation as social learning. Journal of Agricultural Education and Extension. http://dx.doi.org/10.1080/1389224X.2014.939201

Bentley, J. W. (2006). Folk experiments. Agriculture and Human Values, 23(4), 451-462. http://dx.doi.org/10.1007/s10460-006-9017-1

Bentley, J. W., Van Mele, P., \& Acheampong, G. K. (2010). Experimental by nature. Rice farmers in Ghana. Human Organization, 69(2), 120-137. http://dx.doi.org/10.17730/humo.69.2.r078vjvqx23675g1

Chambers, R. (1999). Rural Development. Putting the Last First, Essex, UK: Pearson Education Longman Ltd.

Chevalier, J. M., \& Buckles, D. J. (2013). Participatory Action Research: Theory and Methods for Engaged Inquiry, London, UK: Routledge Chapman \& Hall.

Critchley, W. R. S. (2000). Inquiry, initiative and inventiveness: Farmer innovators in East Africa. Physics and Chemistry of the Earth, 25(3), 285-288. http://dx.doi.org/10.1016/S1464-1909(00)00016-2

Critchley, W. R. S., \& Mutunga, K. (2003). Local innovation in a global context: Documenting farmer initiatives in land husbandry through WOCAT. Land Degradation \& Development, 14(1), 143-162. http://dx.doi.org/10.1002/ldr.537

Darnhofer, I. (2014a). Contributing to a transition to sustainability of agri-food systems: Potentials and pitfalls for organic farming. In S. Bellon \& S. Penvern (Eds.), Organic farming, prototype for sustainable agricultures (pp. 439-452) Dordrecht, Germany: Springer. http://dx.doi.org/10.1007/978-94-007-7927-3_24

Darnhofer, I. (2014b). Resilience and why it matters for farm management. European Review of Agricultural Economics, 41(3), 461-484. http://dx.doi.org/10.1093/erae/jbu012

EU SCAR. (2012). Agricultural knowledge and innovation systems in transition - a reflection paper, European Commission, Brusseles, Belgium.

Folke, C., Carpenter, S. R., Walker, B., Scheffer, M., Chapin, T., \& Rockström, J. (2010). Resilience thinking: Integrating resilience, adaptability and transformability. Ecology and Society, 15(4), $20-29$.

Gerber, A., Hoffmann, V., \& Kügler, M. (1996). Das Wissensystem im Ökologischen Landbau in Deutschland: Zur Entstehung und Weitergabe von Wissen im Diffusionsprozeß. Berichte über Landwirtschaft, 74(4), 591-627.

Hoffmann, V., Probst, K., \& Christinck, A. (2007). Farmers and researchers: how can collaborative advantages be created in participatory research and technology development? Agriculture and Human Values, 24(3), 355-368. http://dx.doi.org/10.1007/s10460-007-9072-2

Kummer, S, Milestad, R, Leitgeb, F., \& Vogl, C. R. (2012). Building resilience through farmers' experiments in Organic Agriculture: Examples from Eastern Austria. Sustainable Agriculture Research, 1(2), 308-321. http://dx.doi.org/10.5539/sar.v1n2p308 
Kummer, S., Leitgeb, F., \& Vogl, C. R. (in prep.). Farmers' own research: The example of organic farmers' experiments in Austria. Under review. Journal for Renewable Agriculture and Food Systems.

Lawrence, D., Christodoulou, N., \& Whish, J. (2007). Designing better on-farm research in Australia using a participatory workshop process. Field Crops Research, 104(1-3), 157-164. http://dx.doi.org/10.1016/j.fcr.2007.03.018

Leach, M. , Rockström, J., Raskin, P., Scoones, I., Stirling, A. C., Smith, A., ... Olsson, P. (2012). Transforming innovation for sustainability. Ecology and Society, 17(2), 11-17. http://dx.doi.org/10.5751/ES-04933-170211

Leitgeb, F, Kummer, S., Funes-Monzote, F. R., \& Vogl, C. R. (2014). Farmers' experiments in Cuba. Renewable Agriculture and Food Systems, 29(1), 48-64. http://dx.doi.org/10.1017/S1742170512000336

Leitgeb, F., Funes-Monzote, F. R., Kummer, S., \& Vogl, C. R. (2011). Contribution of farmers' experiments and innovations to Cuba's agricultural innovation system. Renewable Agriculture and Food Systems, 26(4), 354-367. http://dx.doi.org/10.1017/S1742170511000251

McIntyre, A. (2007). Participatory Action Research. Thousand Oaks, CA, USA: SAGE Publications

McIntyre, B. D., Herren, H. R., Wakhungu, J., \& Watson, R. T. (eds.). (2009). International Assessment of Agriculture Knowledge, Science and Technology for Development - IAASTD - Global Report, Washington, USA: Island Press.

Mittelstrass, J. (2011). On transdisciplinarity. Trames, 15(4), 329-338. http://dx.doi.org/10.3176/tr.2011.4.01

Moeskops, B., \& Cuoco, E. (2014). Strategic Research and Innovation Agenda for Organic Food and Farming. Brussels, Belgium: TP Organics.

Moeskops, B., Blake, F., Tort, M-C., \& Torremocha, E. (Eds.) (2014). Action Plan for Innovation and Learning, Brussels, Belgium: TP Organics.

Montgomery, D. C. (2009). Design and Analysis of Experiments (7 th edition). Hoboken, NJ, USA, John Wiley and Sons.

Neef, A., \& Neubert, D. (2011). Stakeholder participation in agricultural research projects: A conceptual framework for reflection and decision-making. Agriculture and Human Values, 28(2), 179-194. http://dx.doi.org/10.1007/s10460-010-9272-z

Ninio, R., \& Vogl, C. R. (2006). Organic farmers'experiments. Learning local knowledge. FWF project proposal. University of Natural Resources and Life Sciences, Vienna, Austria.

ODO - Oxford Dictionaries Online. (2010). Oxford Dictionaries Online. Oxford, UK, Oxford University Press.

Padel, S. (2001). Conversion to organic farming: A typical example of the diffusion of an innovation? Sociologia Ruralis, 40(1), 40-61. http://dx.doi.org/10.1111/1467-9523.00169

Pretty, J. N. (1991). Farmers' extension practice and technology adaptation: Agricultural revolution in 17th-19th century Britain. Agriculture and Human Values, 8(1-2), 132-148. http://dx.doi.org/10.1007/BF01579666

Pretty, J. N. (1995). Participatory learning for sustainable agriculture. World Development, 23(8), 1247-1263. http://dx.doi.org/10.1016/0305-750X(95)00046-F

Pretty, J. N. (1995). Regenerating Agriculture: Policies and Practice for Sustainability and Self-Reliance. London, UK: Earthscan.

Quiroz, C. (1999). Farmer experimentation in a Venezuelan Andean group.

Rajasekaran, B. (1999). Indigenous agricultural experimentation in home gardens of South India: Conserving biological diversity and achieving nutritional security. In G. Prain, S. Fujisaka, \& M. D. Warren (Eds.), Biological and Cultural Diversity. The Role of Indigenous Agricultural Experimentation in Development (pp. 134-146). London. UK: Intermediate Technology Publications. http://dx.doi.org/10.3362/9781780444574.009

Reij, C., \& Waters-Bayer, A. (2001). Farmer Innovation in Africa. A Source of Inspiration for Agricultural Development. London, UK: Earthscan.

Rhoades, R., \& Bebbington, A. (1991). Farmers as experimenters. In B. Haverkort, J. van der Kamp \& A. Waters-Bayer (Eds.), Joining Farmers' Experiments. Experiences in Participatory Technology Development. (pp. 251-253), London, UK: Intermediate Technology Publications.

Rivera, W. M., Qamar, M. K., \& Mwandemere, H. K. (2005). Enhancing Coordination Among AKIS/RD Actors: An Analytical and Comparative Review of Country Studies on Agricultural Knowledge and Information 
Systems for Rural Development (AKIS/RD). Rome, Italy: FAO.

Röling, N., \& Brouwers, J. (1999). Living local knowledge for sustainable development. In G. Prain, S. Fujisaka \& M. D. Warren (Eds.), Biological and Cultural Diversity. The Role of Indigenous Agricultural Experimentation in Development. (pp. 147-157). London. UK: Intermediate Technology Publications. http://dx.doi.org/10.3362/9781780444574.010

Saad, N. (2002). Farmer processes of experimentation and innovation. A review of the literature. CGIAR Systemwide Program on Participatory Research and Gender Analysis, Document number 21.

Sewell, A. M., Gray, D. I., Blair, H. T., Kemp, P. D., Kenyon, P. R., Morris, S. T., \& Wood, B. A. (2014). Hatching new ideas about herb pastures: Learning together in a community of New Zealand farmers and agricultural scientists. Agricultural Systems, 125, 63-73. http://dx.doi.org/10.1016/j.agsy.2013.12.002

Smits, R. E., Kuhlmann, S., \& Shapira, P. (2010). The theory and practice of Innovation Policy - An International Research Handbook, Williston, VT, USA: Edward Elgar Publishing. http://dx.doi.org/10.4337/9781849804424

Spielmann, D. J., \& Birner, R. (2008). How innovative is your agriculture? Using innovation indicators and benchmarks to strengthen national agricultural innovation systems. Agriculture and Rural Development Diskussion Paper No. 41. The International Bank for Reconstruction and development / The World Bank, Washington, USA.

Stolzenbach, A. (1999). The indigenous concept of experimentation among Malian farmers. In G. Prain, S. Fujisaka \& M. D. Warren (Eds.), Biological and Cultural Diversity. The Role of Indigenous Agricultural Experimentation in Development (pp. 163-171). London. UK: Intermediate Technology Publications. http://dx.doi.org/10.3362/9781780444574.012

Sturdy, J. D., Jewitt, G. P. W., \& Lorentz, S. A. (2008). Building an understanding of water use innovation adoption processes through farmer-driven experimentation. Physics and Chemistry of the Earth, 33, 859-873. http://dx.doi.org/10.1016/j.pce.2008.06.022

Sumberg, J., \& Okali, C. (1997). Farmers' Experiments: Creating Local Knowledge. London, UK: Lynne Rienner Publishers Inc.

Sumberg, J., Okali, C., \& Reece, D. (2003). Agricultural research in the face of diversity, local knowledge and the participation imperative: Theoretical considerations. Agricultural Systems, 76(2), 739-753. http://dx.doi.org/10.1016/S0308-521X(02)00153-1

Tress, G., Tress, B., \& Fry, G. (2005). Clarifying integrative research concepts in landscape ecology. Landscape Ecology, 20(4), 479-493. http://dx.doi.org/10.1007/s10980-004-3290-4

Tulloch, A. I. T., Joseph, L., Szabo, J. K., Martin, T., \& Possingham, H. P. (2013). Realising the full potential of citizen science monitoring programs. Biological Conservation, 165, 128-138. http://dx.doi.org/10.1016/j.biocon.2013.05.025

van de Kerkhof, M., \& Wieczorek, A. (2005). Learning and stakeholder participation in transition processes towards sustainability: Methodological considerations. Technological Forecasting and Social Change, 72(6), 733-747. http://dx.doi.org/10.1016/j.techfore.2004.10.002

Vogl, C. R., Kilcher, L., \& Schmidt, H.-P. (2005). Standards and regulations of organic farming: Moving away from small farmers' knowledge? Journal for Sustainable Agriculture, 26(1), 5-26. http://dx.doi.org/10.1300/J064v26n01_03

Warren, M. D. (Eds.). Biological and Cultural Diversity. The Role of Indigenous Agricultural Experimentation in Development. London, UK: Intermediate Technology Publications.

Wortmann, C. S., Christiansen, A. P., Glewen, K. L., Hejny, T. A., Mulliken, J., Peterson, J. M., ... Zoubek, G. L. (2005). Farmer research: Conventional experiences and guidelines for alternative agriculture and multi-functional agro-ecosystems. Renewable Agriculture and Food Systems, 20, 243-251. http://dx.doi.org/10.1079/RAF2005110

\section{Copyrights}

Copyright for this article is retained by the author(s), with first publication rights granted to the journal.

This is an open-access article distributed under the terms and conditions of the Creative Commons Attribution license (http://creativecommons.org/licenses/by/3.0/). 